\title{
The role of propionate and acetate in the control of food intake in sheep
}

\author{
BY D. A. H. FARNINGHAM AND C. C. WHYTE \\ The Rowett Research Institute, Greenburn Road, Bucksburn, Aberdeen AB2 9SB
}

(Received 22 January 1992 - Accepted 18 September 1992)

\begin{abstract}
Sheep fed ad lib. on a good-quality pelleted diet $(\mathrm{g} / \mathrm{kg}$; hay 500 , barley 300 , molasses, fish meal and minerals) were infused via the hepatic portal vein with mixtures of the sodium salts of volatile fatty acids, acetate and propionate, and a variety of equivalent osmotic loads. Propionate infused at rates between 0.6 and $2.5 \mathrm{mmol} / \mathrm{min}$ consistently reduced food intake in a linear, dose-related manner. Propionate infusions resulted in consistent dose-related increases in peripheral venous plasma glucose concentration but variable changes in insulin concentration. Infusion of osmotically balanced mixtures of propionate, acetate, mannitol or saline $(9 \mathrm{~g} \mathrm{NaCl} / \mathrm{l})$ indicated that at constant osmotic loading propionate caused a greater reduction in intake than other infusions. Acetate infusions only depressed food intake when administered as a $1 \mathrm{M}$ solution. Lower concentrations had little effect, similar to that of equivalent osmotic loads of mannitol or saline. It is concluded that portal propionate flow has a potential role in the control of food intake in ruminants which is independent of osmotic effects or changes in plasma insulin concentration.
\end{abstract}

Food intake: Propionate: Sheep

It has been thought for many years that volatile fatty acids may be involved in the control of food intake in ruminants (for review, see Baile \& Forbes, 1974). Teleologically, a role for volatile fatty acids in satiety is appropriate as they are the major energy products of an extensive fermentation in the rumen and caecum. The liver is ideally placed to monitor and regulate absorptive supply in response to the needs of the animal. Such a role would require mechanisms to link nutrient supply to the central control of feeding behaviour.

Russek (1963) proposed the existence of a hepatostatic mechanism by which glucose regulates feeding in simple-stomached animals, acting via the vagus nerve. However, this theory remains controversial (Bellinger, 1981; Koopmans, 1984) as there is conflicting information in the literature, reviewed by Novin et al. (1985). Recent studies provide support for the hepatostatic mechanism, demonstrating that whereas portal infusion of glucose in rats reduces food intake, peripheral infusion does not; portal infusion also resulted in increased hepatic glycogen content (Tordoffet al. 1989). In addition, it is known that afferent fibres in liver and abdominal viscera are sensitive to glucose and circulating hormones such as cholecystokinin and insulin (Niijima, 1982, 1983). It has been suggested that metabolites such as pyruvate, related to the glycolytic chain (Russek, 1981), or hepatic glycogen flux (Novin et al. 1985), provide a satiety signal which is mediated through afferent hepatic nerves.

Unlike simple-stomached animals, ruminants do not seem to be responsive to glucose infusions, although there is evidence of a role for volatile fatty acids since many studies have shown that infusions into the rumen reduce food intake (Baile $\&$ Forbes, 1974). Fewer studies of the effect of portal infusions have been made. Nevertheless, there is evidence that portal infusions of propionate act through hepatic nerves to inhibit food intake in the sheep 
(Anil \& Forbes, 1980, 1984, 1988). In goats, however, a detailed study was not able to corroborate these findings (De Jong et al. 1981) and, as with glucose infusions in the rat, it has been suggested that the satiety effects of portal infusions of volatile fatty acid may be the result of administration of a hypertonic load (Grovum \& Bignell, 1989). Although it appears that an osmotic load will indeed reduce intake, in the rat it appears that glucose infusions cause a greater reduction in food intake than that due to osmotic loading alone (Tordoff et al. 1989).

In order to separate satiety effects due to hypertonia from mechanisms regulated by volatile fatty acids or their metabolites, comparisons were made between glucogenic propionate, lipogenic acetate and equimolar saline $(9 \mathrm{~g} \mathrm{NaCl} / 1)$ infusions into the portal vein of sheep offered a good-quality diet. A provisional report of some of the findings has been presented (Farningham, 1990).

\section{MATERIALS AND METHODS}

Animals

Female Suffolk cross sheep, reared outside, were housed indoors and then acclimatized to long-term restraint in metabolism crates. Animals were not kept in crates for more than 12 weeks without periods of rest in floor pens. At the time of surgery the animals were approximately 9 months old, weighing $40-50 \mathrm{~kg}$ and in good bodily condition. Some of the animals were used in several of the experiments. The interval between successive experiments ranged from 1 to 16 weeks. The infusions were carried out when the animals were between 11 and 18 months of age and weighed between 60 and $90 \mathrm{~kg}$.

\section{Surgery}

Feed intake was restricted around the time of surgery and animals were starved for $36 \mathrm{~h}$ before preparation with hepatic portal catheters. Anaesthesia was induced with thiopentone and maintained with halothane-nitrous oxide administered through an endotracheal tube. The small intestine was exposed via a right paracostal incision and a catheter introduced into the portal vein via a mesenteric branch (polyvinyl tubing $1.5 \mathrm{~mm}$ i.d., $2.5 \mathrm{~mm}$ o.d.; Dural Plastics, Auburn, NSW, Australia). The catheter was inserted until the tip lay in the region of the porta hepatis, caudal to the liver; correct positioning was determined by radiography or palpation and subsequently confirmed at postmortem. Animals were routinely treated with analgesics and antibiotics postsurgery. Catheter patency was maintained by twice-weekly flushing with physiological saline containing sodium heparin $(1000 \mathrm{iu} / \mathrm{ml})$. Infusions did not start until at least 4 weeks after surgery.

\section{Feed}

Animals were fed on a pelleted diet offered $a b l i b .(\mathrm{g} / \mathrm{kg}$; hay 500 , ground barley 300 , molasses 100 , white fish meal 90 and minerals; dry matter (DM) 870 ; proximate analysis $(\mathrm{g} / \mathrm{kg} \mathrm{DM})$ : crude fibre 197 , crude protein $(\mathrm{N} \times 6.25) 125$, ash 67 , diethyl ether extract 20$)$. Metabolizable energy (ME) determined by indirect calorimetry on previous batches of this mixture gave values of $11.4 \mathrm{MJ} / \mathrm{kg} \mathrm{DM}$. In the morning, refusals from the night before were weighed and discarded, fresh food was offered at 09.30 hours and again at 16.30 hours. The amount of food offered exceeded voluntary intake by at least $300 \mathrm{~g} / \mathrm{d}$.

\section{Analyses}

Blood samples were taken by jugular puncture into evacuated lithium heparinized tubes, plasma was separated at $4^{\circ}$ and stored at $-20^{\circ}$ before analysis. Plasma insulin was determined by radioimmunoassay (Ref. 65-104; ICN Flow, High Wycombe, Bucks.) using 
${ }^{125}$ I-labelled insulin (Amersham International, Aylesbury, Bucks.) and porcine insulin (Sigma Chemical Co. Ltd, Poole, Dorset) as standard. The sensitivity of the assay was $0 \cdot 27 \mu \mathrm{U}$ per tube, the inter- and intra-assay coefficients of variations were 8.3 and $3 \cdot 2 \%$. Glucose was measured using the glucose oxidase (EC 1.1.3.4) method (Trinder, 1969) using a Kone Selective Chemistry Analyser.

\section{Infusions}

Volatile fatty acid solutions for infusion were adjusted to $\mathrm{pH} 7 \cdot 40$ with $\mathrm{NaOH}$ and made to the required concentration. Infusates were passed through a $0.2 \mu \mathrm{m}$ filter and autoclaved before infusion. Infusions were made using peristaltic pumps which were calibrated on a daily basis. Infusion lines were cold-sterilized with benzalkonium chloride $(1: 1000, \mathrm{w} / \mathrm{v})$ before use. In all experiments infusions started $5 \mathrm{~min}$ before offering the morning feed at 09.30 hours and ended $3 \mathrm{~h}$ after feeding, immediately after blood samples had been taken and food intake recorded.

\section{Expt 1}

Five animals were infused with $1 \mathrm{M}$-propionate at $0.6,0.9,1.2,1.8$ or $2.5 \mathrm{ml} / \mathrm{min}$ for $3 \mathrm{~h}$. Treatments were completely randomized, subject to minimizing duplication on infusion days or within an animal in the same week. Each animal received every treatment at least twice. The intention was that control measurements would be determined on Mondays, Wednesdays and Fridays and infusions on the intervening days. The experiment was carried out over two 7-week periods, 16 weeks apart. The interval between treatment impositions ranged from 1 week (within periods) to 21 weeks (between periods). The data were analysed using analysis of variance techniques for an unbalanced incomplete block design where blocks were the individual animal $\times$ week combinations. For most blocks there were three values, the mean for the control during that week and two treatment values.

\section{Expt 2}

Six animals were infused with $1 \mathrm{M}$-propionate or -acetate at 1.2 or $2.5 \mathrm{ml} / \mathrm{min}$, or a $50: 50$ $(\mathrm{v} / \mathrm{v})$ mixture of $1 \mathrm{M}$-acetate and -propionate at $2.5 \mathrm{ml} / \mathrm{min}$. Venous blood samples were collected at the end of the infusion period and at a similar time on control days. Four of the infusions were administered only once to individual animals because of technical problems. The experiment was carried out over a single 11-week period. The interval between replicate treatment impositions was $1-4$ weeks. Otherwise the experimental design and statistical analysis were similar to Expt 1.

\section{Expt 3}

Five animals were infused with $1 \mathrm{~m}$ mixtures of propionate and acetate in the molar ratios $0: 1,1: 3,1: 1,3: 1$ or $1: 0$ at a constant infusion rate of $2.4 \mathrm{ml} / \mathrm{min}$. This gave propionate:acetate delivery rates of $0: 2 \cdot 4,0 \cdot 6: 1 \cdot 8,1 \cdot 2: 1 \cdot 2,1 \cdot 8: 0.6$ and $2 \cdot 4: 0 \mathrm{mmol} / \mathrm{min}$. Blood samples were taken as in Expt. 2. Treatments were randomized and alternated with control days. Animals started the experiment with either an infusion or control measurement so that every day of the experiment was used for infusions. Once an animal had received all treatments the procedure was immediately repeated, so for each animal two complete replicates were obtained in two consecutive $14 \mathrm{~d}$ periods. The interval between repetitions of a treatment in an animal ranged over 3-21 d. For statistical analysis the two replicates were treated as blocks, there were five $\times$ two, i.e. ten blocks in all. For each block a mean control value was calculated and the data were analysed using the analysis of variance for a randomized block design. 
Expt 4

In this experiment seven sheep were used. Since mannitol is non-ionic and only provides half the osmotic load of equimolar volatile fatty acid solutions, it was infused as a $1 \mathrm{M}$ solution and compared with infusions of $0.5 \mathrm{M}$-acetate, propionate and saline infused at $4.8 \mathrm{ml} / \mathrm{min}$. Additionally infusions of $0.15 \mathrm{M}$-saline, an equivalent load of $\mathrm{NaCl}$, were made at $15.6 \mathrm{ml} / \mathrm{min}$. The experimental design and analysis was similar to that employed in Expt 3 ; however, there were three missing values.

\section{Statistical analyses}

Experiments were analysed using Genstat 5.22. Two-tailed tests were used for all comparisons. The figures show the Genstat predicted means with their standard errors for Expts 1 and 2; these values were also used to make planned comparisons between means. In Expts 3 and 4, standard errors of difference were used for making planned comparisons. Regression analysis was applied to the predicted means (Expt 1) or the calculated means (Expt 3).

\section{RESULTS}

\section{Expt 1}

Infusion of propionate caused a dose-related depression in $3 \mathrm{~h}$ food intake $(P<0.001$; Fig. 1). The values were fitted by linear regression; $Y=-65$ (SE 10) $X+241$ (SE 14), $r 0.96$, where $Y$ is $3 \mathrm{~h}$ food intake $(\mathrm{g})$ and $X$ is propionate dose $(\mathrm{mmol} / \mathrm{min})$. Inspection of Fig. 1 shows that the $3 \mathrm{~h}$ food intake might also have been described by a classical sigmoid dose-response curve. Over $24 \mathrm{~h}$, intake was also depressed $(P<0.01)$. Comparison with control values indicates significant depression of $3 \mathrm{~h}$ food intake at infusion rates greater than $0.9 \mathrm{mmol} / \mathrm{min}(P<0.02)$ and $24 \mathrm{~h}$ intake at $1.2 \mathrm{mmol} / \mathrm{min}$ and above $(P<0.05)$. Analysis of variance applied to the $21 \mathrm{~h}$ post-treatment period did not reveal significant effects on food intake after the infusion had stopped.

\section{Expt 2}

The effect of infusion on $3 \mathrm{~h}$ food intake was highly significant $(P<0.001$; Fig. 2$)$. Propionate significantly inhibited food intake compared with the control values at both levels of infusion $(P<0.001)$, as did acetate $(P<0.05$ and $P<0.001$ at 1.2 and $2.4 \mathrm{mmol} / \mathrm{min}$ respectively), but on average to only half the extent of propionate. Infusion of the acetate propionate mixture reduced intake significantly less than $2.5 \mathrm{mmol}$ propionate $/ \mathrm{min}$ alone $(P<0.05)$. Infusion had a significant effect on $24 \mathrm{~h}$ food intake $(P<0.05)$; however, the effects of the lower level of propionate and the acetate-propionate mixture were not significant compared with control values. Both plasma insulin $(P<0 \cdot 01)$ and glucose $(P<0 \cdot 001)$ were significantly altered by infusion. Relative to control values, propionate infusion was associated with increases in plasma concentrations of insulin $(P<0.01)$ and glucose $(P<0.05$ and $P<0.001$ at 1.2 and $2.4 \mathrm{mmol} / \mathrm{min}$ respectively $)$ whereas acetate and the acetate propionate mixture were not.

\section{Expt 3}

In this experiment results were expressed in terms of propionate: total volatile fatty acid $(\mathrm{VFA})$ infused $\left(\mathrm{VFA}_{\mathrm{R}}\right)$. Treatment significantly affected $3 \mathrm{~h}$ intake $(P<0.001)$. Reduction in food intake was greatest at the highest VFA $_{\mathrm{R}}$ studied (Fig. 3). The values of $3 \mathrm{~h}$ food intake for infusion days only were fitted to a linear regression: $Y=-116$ (SE 28) $X+393$ (SE 17), $r 0.92$; where $Y$ is $3 \mathrm{~h}$ food intake $(\mathrm{g})$ and $X$ is $\mathrm{VFA}_{\mathrm{R}}$. Intake at $24 \mathrm{~h}$ was slightly, but not significantly, reduced by the treatments. There was an increase in blood glucose 

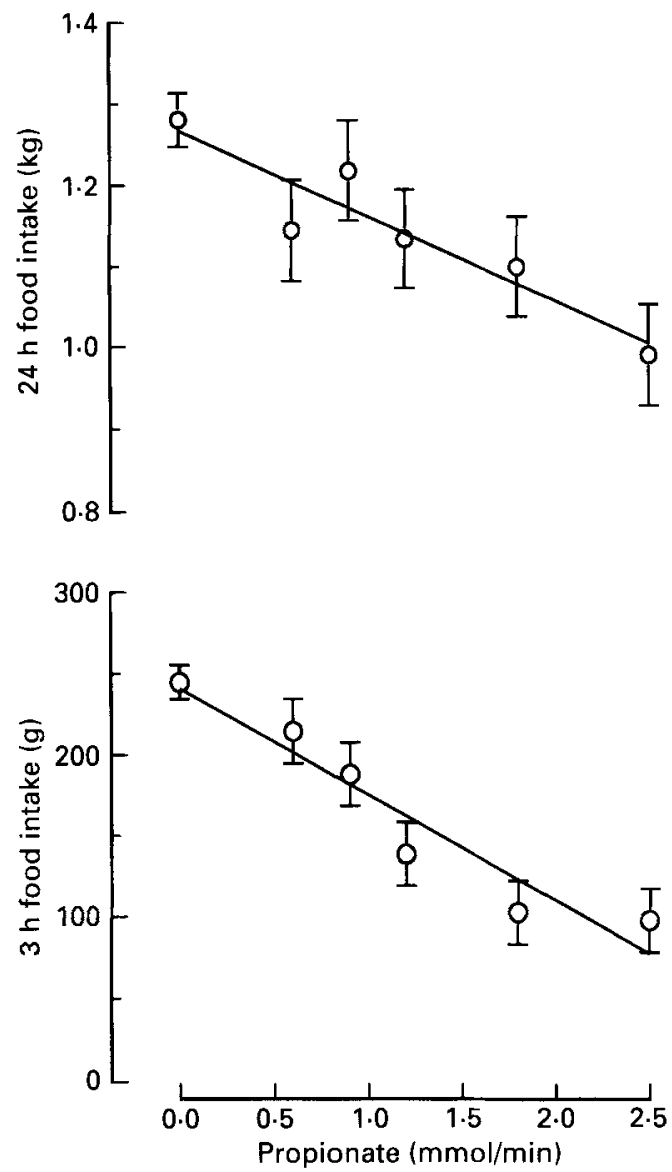

Fig. 1. Expt 1. The effect of $3 \mathrm{~h}$ infusions of propionate on 3 and $24 \mathrm{~h}$ food intake of five sheep. Values are means with their standard errors represented by vertical bars.

concentration in response to increasing $\operatorname{VFA}_{\mathrm{R}}(P<0.001)$. Insulin levels were also altered by the infusions $(P<0.02)$. Significant reduction in insulin compared with control values occurred at lower levels of $\mathrm{VFA}_{\mathrm{R}}\left(P<0.05, P<0.01\right.$ at $\mathrm{VFA}_{\mathrm{R}}$ of 0.25 and 0.0 respectively $)$.

\section{Expt 4}

Infusion had a significant effect on $3 \mathrm{~h}$ food intake $(P<0 \cdot 01 ;$ Fig. 4$)$. Only propionate infusion significantly altered $3 \mathrm{~h}$ food intake; the effect was significant compared with control $(P<0.05)$ and all other treatments $(P<0.01)$. There was no significant effect on $24 \mathrm{~h}$ food intake.

\section{DISCUSSION}

This investigation clearly demonstrates reduction in food intake by propionate at infusion rates between 0.6 and $2.5 \mathrm{mmol} / \mathrm{min}$. Furthermore, the effect was not simply due to osmotic loading since propionate depressed food intake more than equimolar doses of acetate, mannitol, isotonic or hypertonic saline.

Measurements of propionate production and absorption have shown that at rumen production rates of $1 \mathrm{mmol} / \mathrm{min}$, approximately $50 \%$ of propionate is metabolized by the 

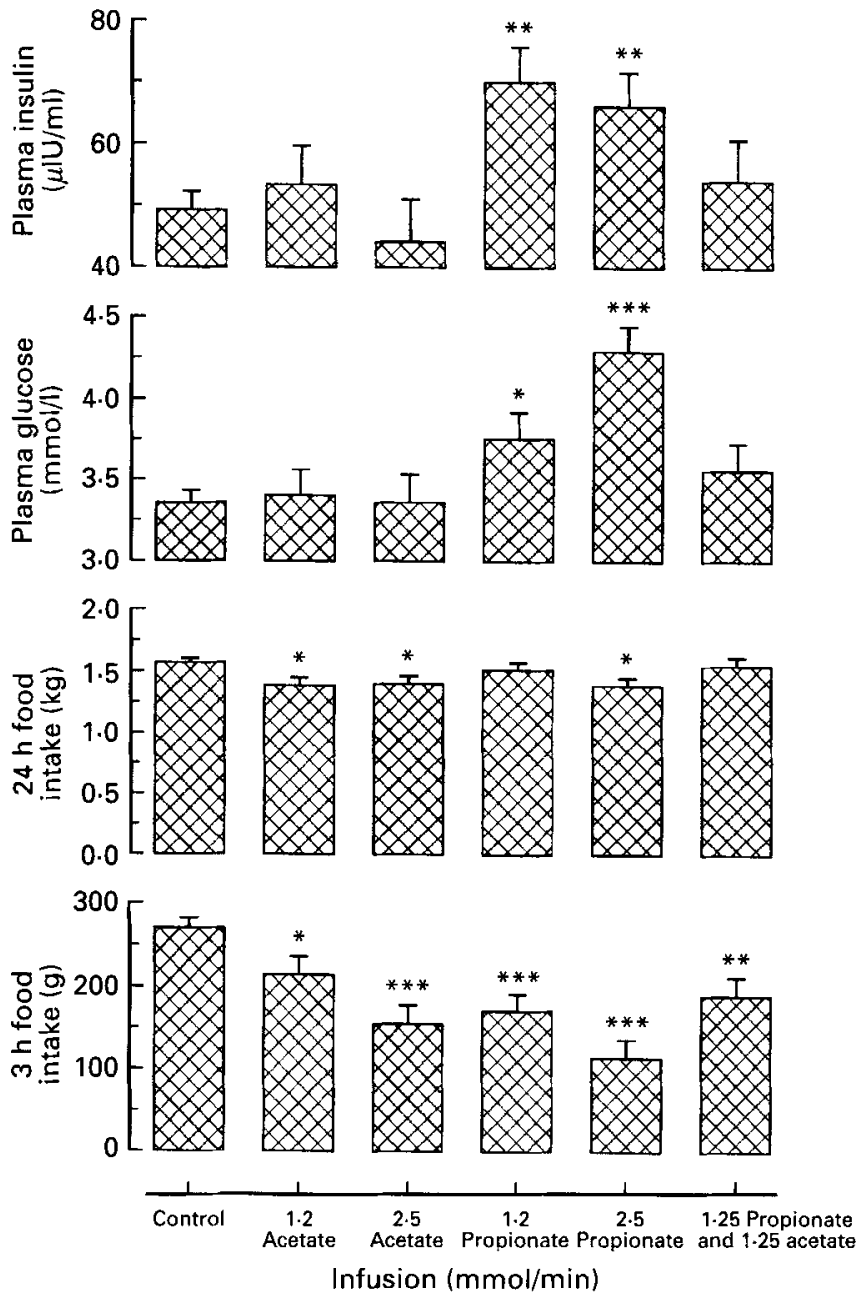

Fig. 2. Expt 2. The effect of $3 \mathrm{~h}$ infusions of propionate and acetate on 3 and $24 \mathrm{~h}$ food intake, plasma glucose and insulin of six sheep. Values are means with their standard errors represented by vertical bars. Treatment means were significantly different from those of non-infused controls: ${ }^{*} P<0.05,{ }^{* *} P<0.01,{ }^{* * *} P<0.001$.

rumen epithelium (Weekes \& Webster, 1975). Bergman et al. (1966) reported that for sheep on maintenance intake portal propionate flow was $7.5 \mu \mathrm{mol} / \mathrm{min}$ per $\mathrm{kg}$. Animals in the present study probably had portal flows of $1.6 \mathrm{mmol}$ propionate $/ \mathrm{min}$. This was calculated from an intake of $1.7 \mathrm{~kg}$ organic matter with a digestibility of 0.70 , which would yield $7 \cdot 3 \mathrm{~mol}$ hexose polymers per d. Proportions of VFA produced were assumed to be 55:35:10 for acetate-propionate-butyrate (Hungate, 1966). The calculations are approximations which assume steady-state nutrition and VFA production, and that only $50 \%$ of propionate produced enters the portal supply to the liver. In the present study animals ate larger meals after the morning feed and so VFA production probably showed circadian fluctuations. Furthermore, assumptions about the extent of rumen wall propionate metabolism are based on studies made in animals which were fasted or fed at maintenance. These rates of propionate metabolism may not be sustained at higher levels of feed intake. 

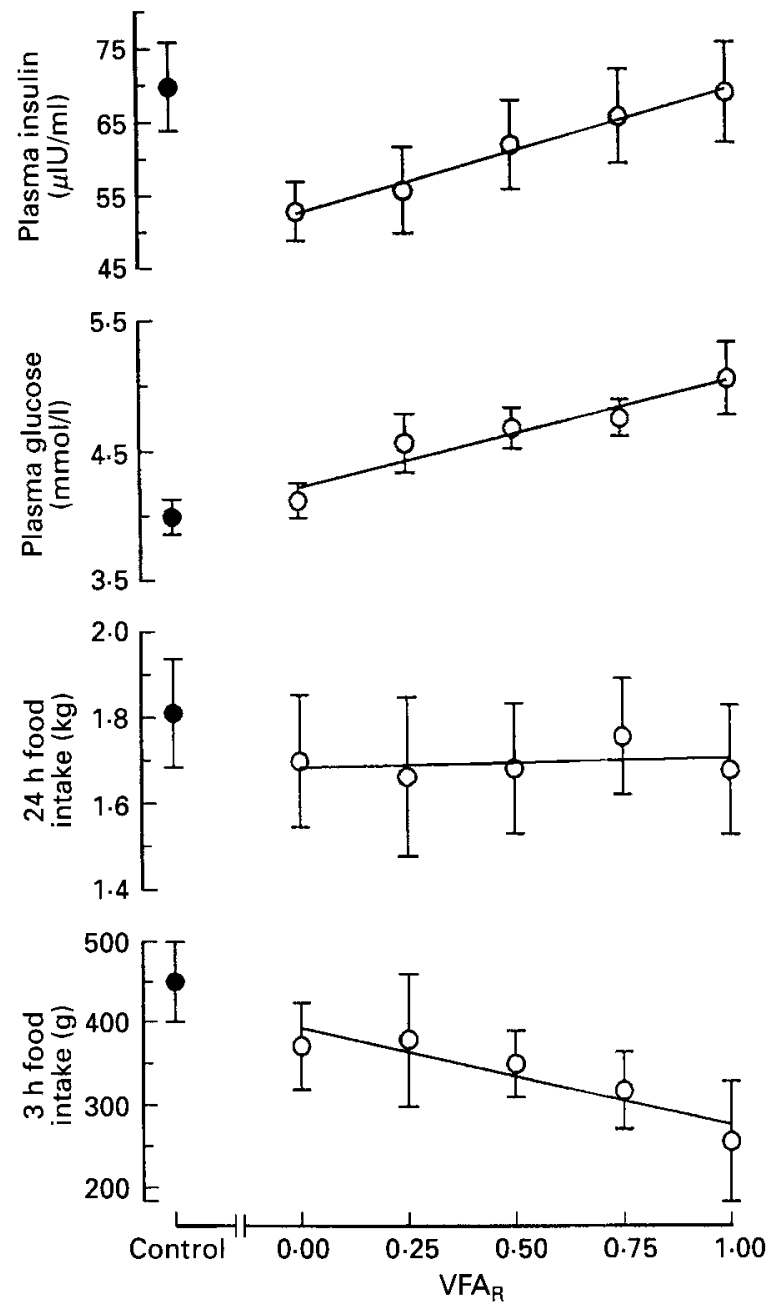

Fig. 3. Expt 3. The effect of infusion of mixtures of propionate and acetate on 3 and $24 \mathrm{~h}$ food intake, plasma insulin and glucose of five sheep. Values are means with their standard errors represented by vertical bars. VFA propionate (mmol): sum of propionate and acetate infused (mmol). The total infusion rate was $2 \cdot 4 \mathrm{mmol} / \mathrm{min}$. (O), Non-infused controls.

Evidence to indicate levels of portal propionate flow that might be expected in animals on a high plane of nutrition can also be estimated from measurements of portal blood flow and portal propionate concentration. Burrin et al. (1989) fed sheep at up to 2.5 times maintenance and demonstrated an association between food intake and portal blood flow. At the highest levels of intake achieved, portal flow was $140 \mathrm{ml} / \mathrm{min}$ per $\mathrm{kg}^{0.75}$ live weight. On this basis, in the current study, portal blood flows of 3 litres $/ \mathrm{min}$ or more are calculated. In goats fed ad lib. De Jong (1981) observed portal propionate concentrations of up to $1 \mathrm{~mm}$. These studies suggest that basal portal propionate flow may in fact have been considerably higher than our estimate of $1.6 \mathrm{mmol} / \mathrm{min}$. Even higher rates of propionate delivery might be observed with, for example, lactating sheep, and so combined exogenous and endogenous propionate flow is unlikely to have exceeded physiological levels except at 

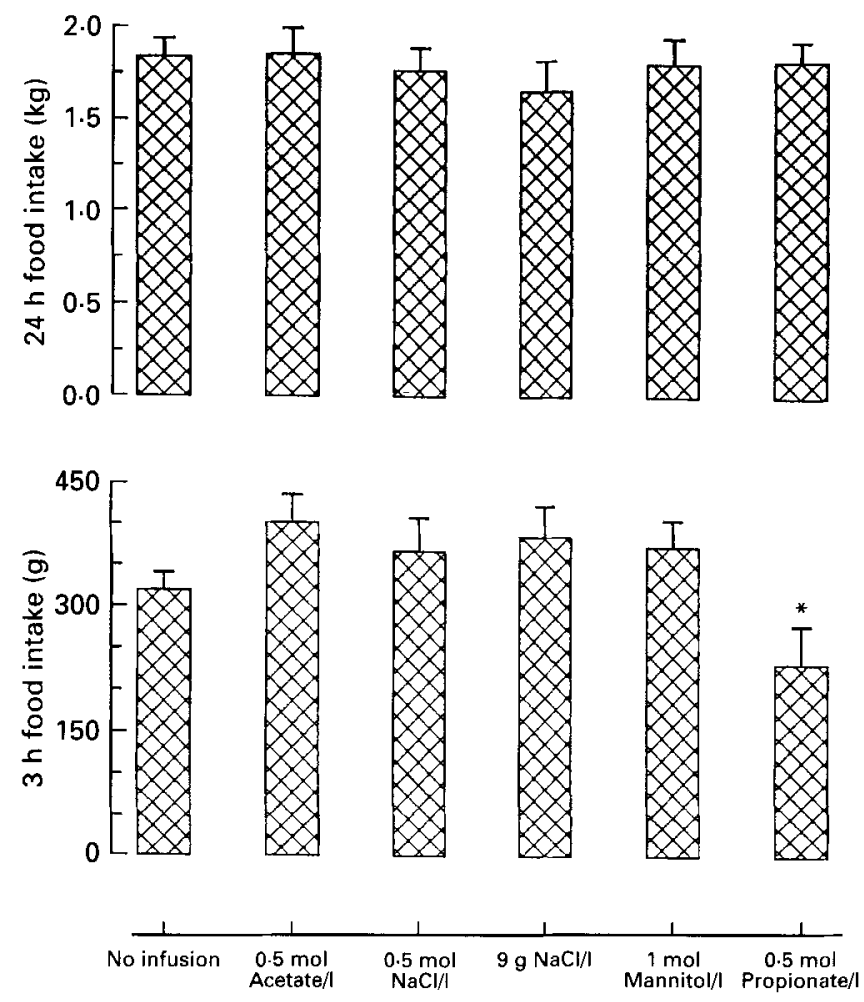

Fig. 4. Expt 4. The effect of different osmotic loads infused for $3 \mathrm{~h}$ at $2.4 \mathrm{mmol} / \mathrm{min}$ on food intake of seven sheep. Values are means with their standard errors represented by vertical bars. Mean value was significantly different from that for controls at $3 \mathrm{~h}$ : $* \boldsymbol{P}<0.05$.

the highest infusion rate. On balance, it seems reasonable to assume that in the current study, rates of exogenous propionate infusion were within the physiological range for our animals.

On the assumption that acetate has little effect on intake, as indicated by Expt 4, the relationship between propionate energy infused and depression of food intake at constant osmotic loading can be calculated from the data in Expt 3. Thus, it appears that the depression in intake was $169 \mathrm{~g} / \mathrm{MJ}$ infused propionate. The ME of the diet was $9.9 \mathrm{~kJ} / \mathrm{g}$ (on an equivalent wet weight basis) and so, in terms of $\mathrm{ME}$, the reduction in energy intake approached twice that infused. Since propionate accounts for approximately $50 \%$ of the available energy from volatile fatty acids and acetate does not seem to reduce food intake, it might be construed that propionate delivery is the major factor governing energy intake. On poor-quality diets, however, both total volatile fatty acid production and propionate proportions are reduced, but animals eat less. In this situation other factors obviously must operate to limit intake.

Propionate consistently caused dose-related increases in plasma glucose, presumably as a result of increased hepatic gluconeogenesis. Increase in post-hepatic propionate might account for the subsequent release of insulin seen in Expt 2, since propionate infused into the peripheral circulation is a more potent stimulus for insulin release than portal infusion (Bergman, 1990). This effect was not seen in the presence of the higher levels of food intake seen in Expt 3. Since these animals were processing larger quantities of feed, the rate of exogenous propionate infusion was proportionally smaller and their livers were probably 
more efficient at extracting propionate in a single pass (Burrin et al. 1990; Demigné et al. 1991). If propionate overflow into the peripheral circulation was thereby prevented, the additional stimulus to insulin release from exogenous propionate would be absent. Since propionate did not consistently elevate plasma insulin but had consistent effects on food intake, it appears that insulin is not involved in propionate satiety.

In Expt 4 mannitol was used as an archetypal osmotic load which is relatively inert but retained within the vascular system and then filtered by the glomerulus without further reabsorption or secretion. The infusion of $0.5 \mathrm{~m}$-acetate per se did not significantly affect intake compared with mannitol or other osmotic loads. Intake effects of acetate were only observed when infused as a $1 \mathrm{~m}$ solution (Expt 2). The effect probably relates to the tonicity of the infusate since the portal vein is sensitive to hypertonic solutions (Baertschi \& Vallet, 1981) and hypertonic saline loads will reduce food intake in the rat (Tordoff et al. 1989). The present findings, therefore, give little support to a potential metabolic role for acetate in the control of food intake.

Acetate infusion had no effect on blood glucose, although there was a tendency in some experiments for acetate infusion to reduce plasma insulin and ameliorate various effects of propionate. Although some interactions occur between different volatile fatty acids, acetate does not affect propionyl-CoA formation (Ash \& Baird, 1973) which could not, therefore, account for such interactions. Animals in the present study were fed ad lib. and were synthesizing substantial amounts of fat; additional infused acetate was probably also used in this way. Fatty acid synthesis requires NADPH which is generated from the pentose phosphate pathway and utilizes glucose. It may be that increased requirements for glucose resulted in partitioning of propionate away from hepatic glycogen which may be involved in the feeding response. Utilization of propionate for NADPH may also be important in determining the insulin responses observed, since animals at higher levels of intake, synthesizing more fat, may utilize more propionate which would not then escape to the periphery to stimulate insulin release.

Some studies reported in the literature were unable to demonstrate any significant reduction of intake by propionate (De Jong et al. 1981; Quigley \& Heitmann, 1991). Generally these studies have reported larger estimates of error than the current study and indeed De Jong et al. (1981), working with goats, observed similar but non-significant reductions in food intake to that predicted by the present work.

There is ample evidence that hepatic metabolism changes in relation to levels of feeding. Liver mass is known to increase markedly at high intake (Burrin et al. 1990) and fasting decreases the capacity of hepatocytes for glucogenesis from propionate (Demigné et al. 1991). In the rabbit Novin et al. (1974) have shown satiety responses to glucose infusions which differ under food-deprived and free-feeding conditions. Furthermore, we have previously shown that the satiety response to propionate can be modulated by cholecystokinin, another factor released in response to a meal (Farningham, 1991). Clearly then, whilst particular energetic relationships have been observed under the conditions of the present experiments, the relationship is unlikely to be constant but will vary with physiological state. Many other factors are involved in the integrated feeding response, and until these factors are understood sufficiently to allow adequate control, the relationship between food intake and energy supply will not be adequately characterized.

In conclusion, we have shown that the sheep is able to sense the rate of delivery of propionate either to the liver or periphery, and adjusts its food intake accordingly. The mechanism by which this effect occurs is not known, but the evidence is against a role for insulin or osmotic pressure changes (Grovum \& Bignell, 1989). By contrast, acetate does not consistently affect food intake when infused portal! and the changes observed with acetate could be explained as a response to osmotic stimulation of the portal vein. 
The authors gratefully acknowledge the technical assistance of Terry Atkinson and Maureen G. Annand for the insulin and glucose analyses and Ian Nevison for statistical advice.

\section{REFERENCES}

Anil, M. H. \& Forbes, J. M. (1980). Feeding in sheep during intraportal infusions of short-chain fatty acids and the effect of liver denervation. Journal of Physiology 298, 407-414.

Anil, M. H. \& Forbes, J. M. (1984). Selective liver denervation and feeding behaviour of sheep. Canadian Journal of Animal Science 64, 343-344.

Anil, M. H. \& Forbes, J. M. (1988). The roles of hepatic nerves in the reduction of food intake as a consequence of intraportal sodium propionate administration in the sheep. Quarterly Journal of Experimental Physiology 73, $539-546$.

Ash, R. \& Baird, G. D. (1973). Activation of volatile fatty acids in bovine liver and rumen epithelium. Evidence for control by autoregulation. Biochemical Journal 136, 311-319.

Baertschi, A. J. \& Vallet, P. G. (1981). Osmosensitivity of the hepatic portal vein area and vasopressin release in rats. Journal of Physiology 315, 217-230.

Baile, C. A. \& Forbes, J. M. (1974). Control of feed intake and regulation of energy balance in ruminants. Physiological Reviews 54, 160-214.

Bellinger, L. L. (1981). Commentary on 'the current status of the hepatostatic theory of food intake control'. Appetite 2, 144-145.

Bergman, E. N. (1990). Energy contributions of volatile fatty acids from the gastrointestinal tract in various species. Physiological Reviews 70, 567-590.

Bergman, E. N., Roe, W. E. \& Kon, K. (1966). Quantitative aspects of propionate metabolism and gluconeogenesis in sheep. American Journal of Physiology 211, 793-799.

Burrin, D. G., Ferrell, C. L., Britton, R. A. \& Bauer, M. (1990). Level of nutrition and visceral organ size and metabolic activity in sheep. British Journal of Nutrition 64, 439-448.

Burrin, D. G., Ferrell, C. L., Eisemann, J. H., Britton, R. A. \& Nienaber, J. A. (1989). Effect of level of nutrition on splanchnic blood flow and oxygen consumption in sheep. British Journal of Nutrition 62, 23-34.

De Jong, A. (1981). Short- and long-term effects of eating on blood composition in free-feeding goats. Journal of Agricultural Science, Cambridge 96, 659-668.

De Jong, A., Steffens, A. B. \& De Ruiter, L. (1981). Effects of portal volatile fatty acid infusions on meal patterns and blood composition in goats. Physiology and Behavior 27, 683-689.

Demigné, C., Yacoub, C., Morand, C. \& Rémésy, C. (1991). Interactions between propionate and amino acid metabolism in isolated sheep hepatocytes. British Journal of Nutrition 65, 301-317.

Farningham, D. A. H. (1990). Effect of hepatic portal infusion of propionate or equivalent saline loads on food intake in sheep. Proceedings of the Nutrition Society 49, 221 A.

Farningham, D. A. H. (1991). Synergism between cholecystokinin octapeptide and propionate in the control of food intake in ruminants. Regulatory Peptides 35, 236.

Grovum, W. L. \& Bignell, W. W. (1989). Results refuting volatile fatty acids per se as signals of satiety in ruminants. Proceedings of the Nutrition Society 48, $3 \mathrm{~A}$.

Hungate, R. E. (1966). The Rumen and its Microbes, 1st ed. New York and London: Academic Press.

Koopmans, H. S. (1984). Hepatic control of food intake. Appetite 5, 127-131.

Niijima, A. (1982). Glucose-sensitive afferent nerve fibres in the hepatic branch of the vagus nerve in the guineapig. Journal of Physiology 332, 315-323.

Niijima, A. (1983). Glucose-sensitive afferent nerve fibers in the liver and their role in food intake and blood glucose regulation. Journal of the Autonomic Nervous System 9, 207-220.

Novin, D., Robinson, K., Culbreth, L. A. \& Tordoff, M. G. (1985). Is there a role for the liver in the control of food intake? American Journal of Clinical Nutrition 42, 1050-1062.

Novin, D., Sanderson, J. D. \& Vanderweele, D. A. (1974). The effect of isotonic glucose on eating as a function of feeding condition and infusion site. Physiology and Behavior 13, 3-7.

Quigley, J. D. \& Heitmann, R. N. (1991). Effects of propionate infusion and dietary energy on dry matter intake in sheep. Journal of Animal Science 69, 1178-1187.

Russek, M. (1963). Participation of hepatic glucoreceptors in the control of food intake. Nature 197, 79-80.

Russek, M. (1981). Current status of the hepatostatic theory of food intake control. Appetite 2, 137-143.

Tordoff, M. G., Tluczek, J. P. \& Friedman, M. I. (1989). Effect of hepatic portal glucose concentration on food intake and metabolism. American Joumal of Physiology 257, R1474-R1480.

Trinder, P. (1969). Determination of glucose in blood using glucose oxidase with an alternative oxygen acceptor. Annals of Clinical Biochemistry 6, 24-27.

Weekes, T. E. C. \& Webster, A. J. F. (1975). Metabolism of propionate in the tissues of the sheep gut. British Journal of Nutrition 33, 425-438. 